\title{
Breast cancer during pregnancy: retrospective institutional case series
}

\author{
Erika Matos ${ }^{1,2}$, Tanja Ovcaricek ${ }^{1}$ \\ ${ }^{1}$ Department of Medical Oncology, Institute of Oncology Ljubljana, Ljubljana, Slovenia \\ ${ }^{2}$ Faculty of Medicine, University of Ljubljana, Ljubljana, Slovenia \\ Radiol Oncol 2021; 55(3): 362-368. \\ Received 29 August 2020 \\ Accepted 29 March 2021 \\ Correspondence to: Assist. Prof. Erika Matos, M.D., Ph.D., Department of Medical Oncology, Institute of Oncology Ljubljana, \\ Zaloska 2, SI-1000 Ljubljana, Slovenia. E-mail: ematos@onko-i.si \\ Disclosure: No potential conflict of interest were disclosed. \\ This is an open access article under the CC BY-NC-ND license (http://creativecommons.org/licenses/by-nc-nd/4.0/).
}

Background. Pregnancy associated breast cancer is a rare disease. It presents a unique entity of breast cancer with aggressive phenotype. The main aim was to evaluate how the international guidelines were followed in daily practice.

Patients and methods. Data concerning patients' and tumours' characteristics, management, delivery and maternal outcome were recorded from institutional electronic database. In this paper a case series of pregnant breast cancer patients treated at single tertiary institution between 2007 and 2019 are presented and the key recommendations on managing such patients are summarized.

Results. Fourteen patients met the search criteria. The majority of tumours were high grade, triple negative or HER2 positive, two patients were de novo metastatic. Treatment plan was made for each patient by multidisciplinary team. Eight patients were treated with systemic chemotherapy with no excess toxicity or severe maternal/fetal adverse effects. In all but two patients, delivery was on term and without major complications. Only one event, which was not in whole accordance with international guidelines, was identified. It was the use of blue dye in one patient.

Conclusions. Women with pregnancy associated breast cancer should be managed like non-pregnant breast cancer patients and should expect a similar outcome, without causing harm to the unborn child. To achieve a good outcome in pregnancy associated breast cancer, a multidisciplinary approach is mandatory.

Key words: breast cancer; pregnancy; clinical characteristics; prognosis; therapeutic strategy

\section{Introduction}

Breast cancer is the most common malignancy among women in the developed world and is one of the most common cancer diagnosis during pregnancy. ${ }^{1,2}$ Nevertheless, it is relatively rare, the reported incidence of pregnancy-associated breast cancer (PABC) is 15 to 35 breast cancer patients per 100,000 births. ${ }^{3,4}$ Although rare, the incidence of $\mathrm{PABC}$ is increasing as women are delaying childbirth. ${ }^{5}$ PABC is defined as breast cancer diagnosed during pregnancy or in the first postpartum year and it represents the second most common malignancy during pregnancy worldwide, second to cervical cancer. ${ }^{1,6}$ Diagnostic and treatment recom- mendations have been mainly based on evidence from retrospective single institutional or small case-control studies and expert consensus, as randomized trials on this entity are understandably lacking. In the present paper, we present a case series of patients diagnosed with breast cancer during pregnancy treated at Institute of Oncology Ljubljana between 2007 and 2019. The aim of the study was to evaluate the adherence of the management of PABC in daily clinical practice to the international clinical guidelines.

Diagnostic procedures for pregnant breast cancer patients should not significantly differ from those for non-pregnant women and the first step in treatment planning is to determine the extent of the 
disease. ${ }^{6}$ As in non-pregnant women, a pathomorphological characterisation of breast cancer is crucial for optimal decision about systemic treatment. Therefore, a core needle biopsy of the tumour has to be done. ${ }^{7}$ The biology of PABC is considered different from that of non-pregnant women with usually more aggressive phenotype. ${ }^{8-12}$ Recommended diagnostic procedures in pregnant woman with breast cancer are presented in Table $1 .^{7}$ Since the incidence of mutation in BRCA 1 or 2 gene is higher in younger breast cancer patients genetic testing should be offered to pregnant women with breast cancer. ${ }^{7,13}$ Once a diagnosis of breast cancer has been made, it is important not to delay treatment. It is recommended that optimal treatment strategy for individual patient is planned by a multidisciplinary team. ${ }^{14}$

There is no epidemiological, clinical or prognostic evidence to suggest that pregnancy, or its termination, will alter the natural history of breast cancer or improve survival. Further, pregnancy by itself need not compromise effective breast cancer treatment, although the selection of and order of modalities need to consider fetal safety. ${ }^{6}$ The most important decision upon diagnosis is thus selection of and order of modalities which need to consider fetal safety. ${ }^{6,14,15}$ The decision about optimal treatment sequence should depend mainly on the extent of the disease and gestational age. Surgery is preferable in the $1^{\text {st }}$ trimester, however, for patients in the $2^{\text {nd }}$ or $3^{\text {rd }}$ trimester, the treatment strategy should depend mainly on the extent of the disease ${ }^{14}$ Historically, a modified radical mastectomy was considered the standard of care for PABC because this approach eliminates the need for postoperative radiotherapy, and definitively managed the axillary region. However, breast conservation is a valid surgical option for many, although limited by the postoperative radiotherapy which is contraindicated during all trimesters of pregnancy.

Systemic treatment should not begin before the end of $1^{\text {st }}$ trimester, upon completion of organogenesis, however chemotherapy in the $2^{\text {nd }}$ and $3^{\text {rd }}$ trimester is considered safe therapeutic options for the majority of patients with PABC and thus postponing treatment until after delivery is not advised since it was associated with a worse outcome of the malignant disease.,16,17 It is recommended to end with chemotherapy before the 36th week of gestation or within 3 weeks of planned delivery to avoid potential hematologic complications at the time of delivery. ${ }^{15}$ The greatest experience of chemotherapy in pregnancy has been with anthracyclines and there is limited data on the use of taxanes in preg- nancy and thus taxane use is not recommended during pregnancy but, if indicated, may be used after delivery.

Endocrine therapy is also not recommended during pregnancy. The literature regarding breast radiotherapy during pregnancy is scarce and according to current international guidelines, radiotherapy is not recommended during pregnancy. ${ }^{7}$ Delivery should be scheduled on the estimated date of delivery. Early induction of delivery is not recommended unless so indicated for other medical reasons. ${ }^{15,18}$ Table 2 presents recommended treatment modality according to gestational age.

Although in the past PABC was thought to have a poor prognosis recent studies showed that prognosis is comparable to non-pregnant patients when adjusted for age and disease stage. ${ }^{18,19}$

\section{Patients and methods}

This is a retrospective case series of patients who were treated for breast cancer at Institute of

TABLE 1. Diagnostic procedures for pregnant breast cancer patients

\begin{tabular}{cc}
\hline Diagnostic procedures & Patients selection \\
\hline Breast US with CNB & All patients \\
Mammography & All patients \\
Chest X-ray & All patients \\
CNB: tumor grade, ER, PR, HER2 status & All patients \\
Laboratory test (CBC, ALP, LFT, CA 15-3) & All patients \\
Liver US & Liver metastases suspected \\
Bone MRI & Bone metastases suspected \\
\hline
\end{tabular}

$\mathrm{ALP}=$ alkaline phosphatase $; \mathrm{CBC}=$ complete blood counts; $\mathrm{CNB}=$ core needle biopsy; $\mathrm{ER}=$ estrogen receptor; LFT = liver function tests; $M R I$ = magnetic resonance imaging; $P R$ = progesterone receptor; US = ultrasound

TABLE 2. Treatment of pregnant breast cancer patients

\begin{tabular}{|c|c|c|c|}
\hline $\begin{array}{l}\text { Gestational } \\
\text { age }\end{array}$ & Surgery & $\begin{array}{l}\text { Systemic } \\
\text { treatment }\end{array}$ & $\begin{array}{c}\text { Treatment after } \\
\text { delivery }\end{array}$ \\
\hline $1^{\text {st }}$ trimester & $\begin{array}{c}\text { Mastectomy } \\
+ \\
\text { SNB/ALND }\end{array}$ & $\begin{array}{l}\text { Adjuvant } \mathrm{ChT} \\
\text { beginning in } \\
2^{\text {nd }} \text { trimester }\end{array}$ & $\begin{array}{c}\text { Adjuvant ET/anti-HER2 } \\
\text { therapy (if indicated) } \\
+ \\
\text { RT (if indicated) }\end{array}$ \\
\hline $\begin{array}{l}2^{\text {nd }} \text { and } \\
3^{\text {rd }} \text { trimester }\end{array}$ & $\begin{array}{c}\text { Mastectomy/BCS } \\
+ \\
\text { SNB/ALND }\end{array}$ & $\begin{array}{c}\text { ChT } \\
\text { (adjuvant/neo- } \\
\text { adjuvant) }\end{array}$ & $\begin{array}{c}\text { Adjuvant ET/anti-HER2 } \\
\text { therapy (if indicated) } \\
+ \\
\text { RT (if indicated) }\end{array}$ \\
\hline $\begin{array}{l}\text { Late } \\
\text { 3rd trimester }\end{array}$ & $\begin{array}{c}\text { Mastectomy/BCS } \\
+ \\
\text { SNB/ALND }\end{array}$ & & $\begin{array}{c}\text { Adjuvant ET/anti-HER2 } \\
\text { therapy (if indicated) } \\
+ \\
\text { RT (if indicated) }\end{array}$ \\
\hline
\end{tabular}

ALND = axillary lymph node dissection; $\mathrm{BCS}=$ breast conserving surgery; $\mathrm{ChT}=$ chemotherapy; $\mathrm{ET}$ = endocrine therapy; $\mathrm{RT}$ = radiotherapy; SNB = sentinel node biopsy 
Oncology Ljubljana between 2007 and 2019 and were pregnant at the time of confirmed malignant disease. Data were recorded from institutional electronic database using the following search criteria: "breast cancer" and "pregnancy" and "gestational" or "breast cancer during pregnancy". Patients and tumours characteristics as well as data about treatment and delivery were collected from individual patient's charts.

Data were analysed applying descriptive statistics. SPSS version 19.0 was used for analysis (IBM, Armonk, NY).

The study was approved by the Institutional Review Board Committee and was carried out according to the Declaration of Helsinki.

\section{Results}

Fourteen patients matched the search criteria in the period between January 1, 2007 and December 31, 2019. The average age of the patients was 33 (from 27 to 39) years. The gestational age upon diagnosis was between 6 and 40 weeks, with an average of 21 weeks. The details of the individual patients regarding the stages and histopathological characteristics of tumours and types of systemic and surgical treatment as well as radiotherapy are listed in Table 3. In almost half of the patients, the tumor was classified as triple-negative and most of the tumours were poorly differentiated. Almost half of the patients had HER2 positive tumours. All patients were offered genetic testing. Ten patients decided to do it. Out of them, four were found to be BRCA1 or BRCA2 gene mutation carriers.

Eight patients received chemotherapy during pregnancy. All were treated with anthracyclines in combination with cyclophosphamide, and only one received taxanes (paclitaxel). As part of supportive treatment, they mainly received antiemetic ondansetron and corticosteroids. Patients tolerated the treatment with no significant adverse effects. In addition to alopecia which was reported in all patients treated with chemotherapy, anaemia was the second most common adverse event, three patients had grade 2 anaemia. ${ }^{20}$

Two patients were diagnosed with primary metastatic breast cancer. In both cases, the disease was detected in the 3rd trimester; they continued with pregnancy and gave birth on term (more than 38 weeks of gestation). Primary metastatic disease was suspected based on symptoms (hip pain) and abnormal laboratory values. Both patients had high levels of tumour marker Ca 15-3 (1673, 157; normal level below $30 \mathrm{kU} / \mathrm{L}$ ) and elevated levels of alkaline phosphatase (ALP; 2.02, 2.91; normal level below $1.74 \mathrm{ukat} / \mathrm{L}$ ) at presentation.

Most of deliveries occurred on the scheduled date, in most cases by vaginal delivery. One patient decided to terminate pregnancy at week 10 to start treatment, one patient gave birth prematurely at week 27 due to placenta praevia. In another patient delivery was induced at week 34 due to recommended adjuvant trastuzumab therapy.

No serious post-natal complications were reported. Twelve patients received systemic treatment (cytostatic, endocrine and/or antiHER2 treatment) post-partum. The median period from delivery to initiation of post-partum systemic treatment was 16 days (from 7 to 24 days). The median follow-up period was 64 months. Two patients died due to breast cancer, one of them was primary metastatic, in the second case, the patient died due to central nervous system relapse that occurred only two months after completion of neoadjuvant chemotherapy and surgery. At presentation there were no signs or symptoms of metastatic disease. All the others continue with regular follow-ups at Institute of Oncology Ljubljana.

\section{Discussion}

In the present paper, we present 14 cases of breast cancer patients diagnosed during pregnancy. With regard to the primary aim of the study, which was to evaluate the adherence of the treatment of PABC in daily clinical practice to the international clinical guidelines, we found that most patients were treated accordingly.

Over the observed period 14 cases were identified. According to the incidences of PABC reported in the literature one would expect between one to five cases per year in Slovenia., ${ }^{2,4}$ The number of cases in our study is low which may be due to case identification method and/or a fact that only patients who were pregnant at the time of diagnosis were included, which does not fit to the definition of PABC. For the purpose of this study, we focused on the management of pregnant women with newly diagnosed breast cancer.

Breast cancer diagnosed during pregnancy is most often detected as a palpable mass. This was true for all our 14 patients. Due to hormonal changes palpation of breasts during pregnancy and breastfeeding is often unreliable and this is one of the reasons why PABC is often diagnosed in more advanced stage in comparison to other patients. ${ }^{6,21}$ 
Diagnostic procedures should not significantly differ from those for non-pregnant women. Breast ultrasound (US) is considered the standard first line imaging modality with known high sensitivity, specificity and safety. ${ }^{22,23}$ Due to the increased density of the breast tissue mammography is less sensitive in this population. ${ }^{24}$ It is indicated for US confirmed solid lesions to determine the spread of calcifications, which is important for surgical treatment planning. By adequate shielding of the abdomen, mammography exposes the fetus to a minimal dose of radiation (0.001-0.01 mGy). ${ }^{25,26}$ Opinions on safety of breast magnetic resonance imaging (MRI) in pregnant women are contradictory ${ }^{27}$ According to the latest guidelines on the use of contrast agents in pregnant women by European

TABLE 3. Individual patients and tumours characteristics with details of treatment

\begin{tabular}{|c|c|c|c|c|c|c|c|c|c|}
\hline Patient & $\begin{array}{l}\text { Patient's } \\
\text { age at BC } \\
\text { diagnosis } \\
\text { (years) }\end{array}$ & $\begin{array}{l}\text { GA at BC } \\
\text { diagnosis } \\
\text { (weeks) }\end{array}$ & $\begin{array}{l}\text { BC stage, } \\
\text { tumor grade }\end{array}$ & $\begin{array}{c}\text { HR } \\
\text { HER2 } \\
\text { BRCA }\end{array}$ & $\begin{array}{l}\text { Systemic } \\
\text { treatment } \\
\text { during } \\
\text { pregnancy }\end{array}$ & $\begin{array}{l}\text { Mode of } \\
\text { delivery }\end{array}$ & $\begin{array}{l}\text { Complications } \\
\text { at delivery, } \\
\text { post-partum }\end{array}$ & $\begin{array}{l}\text { Type of BC } \\
\text { surgery }\end{array}$ & $\begin{array}{l}\text { Post-partum } \\
\text { treatment }\end{array}$ \\
\hline 1 & 34 & 28 & $\begin{array}{c}\text { T2N1M0 } \\
\text { IB } \\
\text { G3 }\end{array}$ & $\begin{array}{l}\text { ER/PR neg } \\
\text { HER2 poz } \\
\text { BRCA pos }\end{array}$ & EC & Vaginal & - & MRM & $\begin{array}{c}\text { Doce, } \\
\text { trastuzumab } \\
\text { RT }\end{array}$ \\
\hline 2 & 28 & 13 & $\begin{array}{c}\text { T2NOMO } \\
\text { IA } \\
\text { G3 }\end{array}$ & $\begin{array}{l}\text { ER/PR neg } \\
\text { HER2 neg } \\
\text { BRCA neg }\end{array}$ & EC & CS & $\begin{array}{l}\text { Placenta } \\
\text { praevia, } \\
\text { delivery at } \\
27 \text { weeks of } \\
\text { gestation }\end{array}$ & $B C S$ and $A L N D$ & $\begin{array}{l}\text { EC, pacli } \\
\text { RT }\end{array}$ \\
\hline 3 & 37 & 32 & $\begin{array}{c}\text { T2NOMO } \\
\text { IIA } \\
\text { G3 }\end{array}$ & $\begin{array}{l}\text { ER/PR neg } \\
\text { HER2 neg } \\
\text { BRCA neg }\end{array}$ & EC & Vaginal & - & BCS and SNB & $\begin{array}{c}\text { EC, pacli } \\
\text { RT }\end{array}$ \\
\hline 4 & 38 & 40 & $\begin{array}{c}\text { T3NIMO } \\
\text { IIIA } \\
\text { G2 }\end{array}$ & $\begin{array}{l}\text { ER/PR pos } \\
\text { HER2 pos } \\
\text { BRCA neg }\end{array}$ & - & Vaginal & - & MRM & $\begin{array}{l}\text { FEC, doce, } \\
\text { trastuzumab, } \\
\text { tamoxifen, RT }\end{array}$ \\
\hline 5 & 27 & 14 & $\begin{array}{l}\text { TINOMO } \\
\text { IA } \\
\text { G3 }\end{array}$ & $\begin{array}{l}\text { ER/PR neg } \\
\text { HER2 neg } \\
\text { BRCA pos }\end{array}$ & EC & Vaginal & - & $\begin{array}{l}\text { Mastectomy } \\
\text { and SNB and } \\
\text { reconstruction } \\
\text { (expander) }\end{array}$ & - \\
\hline 7 & 30 & 24 & $\begin{array}{c}\text { T3NOMO } \\
\text { IIB } \\
\text { G3 }\end{array}$ & $\begin{array}{l}\text { ER/PR neg } \\
\text { HER2 neg } \\
\text { BRCA pos }\end{array}$ & AC, pacli & CS & - & $\begin{array}{l}\text { Mastectomy } \\
\text { and SNB and } \\
\text { reconstruction } \\
\text { (expander) }\end{array}$ & Cape, RT \\
\hline 8 & 32 & 26 & $\begin{array}{c}\text { T4dN2M1 } \\
\text { IV } \\
\text { G2 }\end{array}$ & $\begin{array}{l}\text { ER/PR pos } \\
\text { HER2 pos } \\
\text { BRCA ND }\end{array}$ & $A C$ & Vaginal & - & No surgery & $\begin{array}{l}\text { Doce, } \\
\text { trastuzumab, } \\
\text { tamoxifen, RT }\end{array}$ \\
\hline 9 & 39 & 13 & $\begin{array}{c}\text { T2N1MO } \\
\text { IIB } \\
\text { G2 }\end{array}$ & $\begin{array}{l}\text { ER/PR pos } \\
\text { HER2 neg } \\
\text { BRCA ND }\end{array}$ & $A C$ & Vaginal & - & MRM & $\begin{array}{c}\text { Pacli, } \\
\text { tamoxifen }\end{array}$ \\
\hline 10 & 32 & 30 & $\begin{array}{c}\text { TICNOMO } \\
\text { IA } \\
\text { G3 }\end{array}$ & $\begin{array}{l}\text { ER/PR pos } \\
\text { HER2 neg } \\
\text { BRCA pos }\end{array}$ & - & CS & $\begin{array}{l}\text { Induced } \\
\text { delivery, } 35 \\
\text { weeks of } \\
\text { gestation }\end{array}$ & $\begin{array}{l}\text { Mastectomy } \\
\text { and SNB }\end{array}$ & EC, tamoxifen \\
\hline 13 & 31 & 38 & $\begin{array}{c}\text { T3N2MO } \\
\text { IIIA } \\
\text { G3 }\end{array}$ & $\begin{array}{l}\text { ER/PR neg } \\
\text { HER2 neg } \\
\text { BRCA ND }\end{array}$ & - & Vaginal & - & MRM & FEC, doce, RT \\
\hline 14 & 38 & 36 & $\begin{array}{c}\text { T3N2M1 } \\
\text { IV } \\
\text { G3 }\end{array}$ & $\begin{array}{l}\text { ER/PR pos } \\
\text { HER2 pos } \\
\text { BRCA neg }\end{array}$ & - & Vaginal & - & No surgery & $\begin{array}{l}\text { Doce, } \\
\text { pertuzumab, } \\
\text { trastuzumab, } \\
\text { tamoxifen }\end{array}$ \\
\hline
\end{tabular}

$\mathrm{AC}=$ doxorubicin and cyclophosphamide; $\mathrm{BC}=$ breast cancer; $\mathrm{BCS}=$ breast conserving surgery; $\mathrm{BRCA}=\mathrm{BRCA}$ status; Cape = capecitabine; $\mathrm{CS}=\mathrm{caesarean}$ section; doce = docetaxel; $\mathrm{EC}=$ epidoxorubicin and cyclophosphamide; $\mathrm{ER}=$ estrogen receptor; FEC = 5-fluorourcil, epidoxorubicin and cyclophosphamide; GA = gestational age, HR = hormone receptor status; HER2 = HER2 status; $M R M=$ modified radical mastectomy; $N D=$ not done; $N R=$ not relevant; pacli = paclitaxel; $P R=$ progesterone receptor; $R T=$ radiotherapy; SNB = sentinel lymph node biopsy 
Society of Urogenital Radiology breast MRI using gadolinium-based contrast may be done in pregnant woman and no extra neonatal tests are proposed in these cases. ${ }^{28}$ In none of our patients MRI was performed during pregnancy, however, all of them had breast US and mammography done.

Staging investigations are not routinely indicated in newly diagnosed operable PABC, although if they have symptoms suggestive of distant metastases, selective imaging can be performed, including chest radiograph and an abdominal US. When bone metastases are suspected, MRI is currently a preferred diagnostic modality. ${ }^{26}$ In two of our patients primary metastatic disease was suspected at presentation based on elevated levels of tumour marker Ca 15-3 and abnormal values of ALP. In one patient abdominal US and lung $\mathrm{X}$-ray were performed during pregnancy, both were normal. Although bone metastases were suspected due to reported pain in her left hip, skeletal MRI was not performed, since at that time it was not regarded as safe diagnostic procedure during pregnancy. However, bone scan, the standard diagnostic procedure for detection of bone metastases at that time, was postponed until after delivery when bone metastases were confirmed. In second patient breast cancer was diagnosed close to the end of pregnancy, therefore, staging of breast cancer was performed postpartum and included abdominal and thoracic CT. Liver metastases were diagnosed and were later on confirmed by fine needle aspiration biopsy.

As in non-pregnant women a pathomorphological characterisation of breast cancer is crucial for optimal decision about systemic treatment. ${ }^{7}$ Core needle biopsy of the tumor was performed in all 14 patients from our series. The biology of PABC is considered different from that of non-pregnant women. ${ }^{8}$ These tumours usually present with more aggressive phenotype. They are frequently poorly differentiated, estrogen-receptor negative, of either triple-negative or HER2 positive subtype. Therefore, the disease is often diagnosed at higher stage. ${ }^{9-12}$ The majority of our patients had poorly differentiated tumours and almost half had a triple-negative breast cancer subtype, which is in concordance with other reports. ${ }^{7,11,12,14}$ As per guidelines genetic testing has been offered to all patients since it is known that the incidence of mutation in BRCA 1 or 2 gene is higher in younger breast cancer patients and was performed in 10 patients, 4 of them were positive for germline BRCA mutations. In general, however, there is a lack of studies on this topic and its incidence in PABC is unknown. Beside that it is unclear how the knowledge of germ line mutations in established PABC may affect treatment decisions, especially with regard to risk-reducing operative procedures and/ or systemic treatments. On the other hand, genetic testing results may however affect the extent of breast surgery and regimen of further follow-up.7,13

Once a diagnosis of breast cancer has been made, it is important not to delay treatment. As recommended, the optimal treatment strategy for all of our 14 patients was planned by a multidisciplinary board, which consisted of surgical oncologist, medical oncologist, radiotherapist and gynaecologist. ${ }^{14}$ Per guidelines surgery can be safely performed in all three trimesters. Mastectomy and breast-conservation surgery are both safe, while breast reconstruction surgery is not recommended during pregnancy.,14,24,29 The extent of axillary surgery should follow the same guidelines that apply to the rest of the breast cancer population. ${ }^{14,30,31}$ In patients with clinically negative axillary lymph nodes, sentinel lymph node biopsy is the method of choice to minimize the likelihood of lymphedema. Data about the safety of this procedure in pregnant patients are limited, but mostly show that this approach is safe if used in modified manner. ${ }^{32,33}$ The safety of radioactive tracer (eg technetium $99 \mathrm{~m}$ sulphur colloid) during pregnancy was verified by measuring the uterine dose of radiation from lymphoscintigraphy. Doses were found to be much lower than teratogenic threshold. Therefore, some experts believe sentinel lymph node biopsy should be considered standard of care in clinically negative axilla. ${ }^{34}$ On the contrary, the use of any dye is not permitted during pregnancy due to concern for maternal anaphylaxis and the possibility for teratogenicity. ${ }^{14,31,34}$ We found that in regard of surgery our patients were mostly treated in accordance to current clinical guidelines, but some minor deviations were detected. ${ }^{7,14,24}$ In one patient blue dye was used to detect the sentinel lymph node. Sentinel node biopsy was performed in five patients, in two of them also breast reconstruction with expanders placed during the initial mastectomy. Although according to current guidelines breast reconstruction surgery should not be performed during pregnancy small studies support the safety of immediate expander placement with improved psychologic and aesthetic outcomes. ${ }^{31,32,35}$

The literature regarding breast radiotherapy during pregnancy is scarce and radiotherapy is according to current international guidelines contraindicated during pregnancy. However, some authors believe that modern approaches, such as 
3D-conformal radiotherapy (3DCRT) or intraoperative radiotherapy (IORT), can be considered during the first two trimesters in selected cases. ${ }^{36}$ None of our patients received radiotherapy during pregnancy.

Eight of our patients received chemotherapy during pregnancy. According to guidelines systemic treatment should follow the recommendations that apply to the rest of the breast cancer population. It should not begin before the end of 1st trimester, upon completion of organogenesis., ${ }^{716}$ Postponing treatment until after delivery may be associated with a worse outcome of the malignant disease and is therefore not advised..$^{37,38}$ The dosage is supposed to be calculated according to the patient's actual body weight and the intervals should remain the same as for non-pregnant patients. ${ }^{39}$ Pregnancy is not a restraining factor for treatment with a dose-dense regimen supported by granulocyte growth factors. However, more frequent blood counts tests are advised due to the risk of anaemia and neutropenia. ${ }^{15,40}$ Use of anthracyclines and cyclophosphamide during pregnancy was found to be safe, regarding the safety of other cytotoxic drugs during pregnancy data are scarce. ${ }^{41-43}$ Most of the reports on taxanes relate to the safety of paclitaxel. ${ }^{44,45}$ Use of trastuzumab is contraindicated during pregnancy due to increased occurrence of oligo and anhydramnion. The same applies to other anti-HER2 therapy. ${ }^{15,46}$ Endocrine therapy is also not permitted during pregnancy due to many reported developmental abnormalities, particularly with tamoxifen treatment. $15,47,48$

Among anti-emetics, ondansetron is classified as group B drug in terms of safety during pregnancy and metoclopramide is also recognized to be safe. ${ }^{49,50}$ Data regarding safety of glucocorticoids during pregnancy are conflicting, some favour the use of methylprednisolone. ${ }^{51}$

Systemic treatment of pregnant patients from our cohort was based on anthracyclines and did not start before the end of 1st trimester. One patient also received taxanes. Although some experts still warn about the routine use of taxanes in pregnant women, some case reports series suggest similar safety profiles of taxanes to doxorubicin. ${ }^{45}$ Therefore, we do not consider this approach as guidelines violation. None of our patients received endocrine or anti-HER2 therapy during pregnancy.

In the past, PABC was thought to have a poor prognosis. ${ }^{18}$ Multiple less extensive, retrospective cohort and case-control studies conducted in recent decades have demonstrated different findings. When adjusted for age, disease stage and morpho- logical characteristics of the tumours many studies have failed to demonstrate a significantly worse outcome for women who were diagnosed with early and locally advanced breast cancer during pregnancy compared to non-pregnant patients. ${ }^{19}$ On the contrary, prognosis of metastatic PABC is generally poor and the expected 5-year survival is only about $10 \%$.

Although the median follow-up period in our case series is fairly short and the sample size small and thus is impossible to assess the impact of PABC on prognosis of these patients. However, no breast cancer relapse in initially non-metastatic patients was detected so far. This might suggest no significantly worse prognosis in our series of patients.

\section{Conclusions}

Treatment of breast cancer diagnosed during pregnancy is a major professional and ethical challenge for all members of the multidisciplinary team. We found that the incidence of breast cancer diagnosed in pregnant women was low in the observed period. Patients were mostly treated in accordance with current international clinical guidelines. Only one event that was not in accordance was identified. It was the use of blue dye in one patient. The reason for this event is unknown.

\section{References}

1. Bray F, Ferlay J, Soerjomataram I, Siegel RL, Torre LA, Jemal A. Global cancer statistics 2018: GLOBOCAN estimates of incidence and mortality worldwide for 36 cancers in 185 countries. CA Cancer J Clin 2018; 68: 394-424. doi: 10.3322/caac. 21492

2. Lee YY, Roberts CL, Dobbins T, Stavrou E, Black K, Morris J, et al. Incidence and outcomes of pregnancy-associated cancer in Australia, 1994-2008: a population-based linkage study. Bjog 2012; 119: 1572-82. doi: 10.1111/j.14710528.2012.03475.x

3. Stensheim H, Moller B, van Dijk T, Fossa SD. Cause-specific survival for women diagnosed with cancer during pregnancy or lactation: a registry-based cohort study. J Clin Oncol 2009; 27: 45-51. doi: 10.1200/JCO.2008.17.4110

4. Smith LH, Danielsen B, Allen ME, Cress R. Cancer associated with obstetric delivery: results of linkage with the California cancer registry. Am J Obstet Gynecol 2003; 189: 1128-35. doi: 10.1067/s0002-9378(03)00537-4

5. Mathews TJ, Hamilton BE. Mean age of mothers is on the rise: United States, 2000-2014. NCHS Data Brief 2016; 232: 1-8. PMID: 26828319

6. Rojas KE, Bilbro N, Manasseh DM, Borgen PI. A review of pregnancy-associated breast cancer: diagnosis, local and systemic treatment, and prognosis. J Womens Health 2019; 28: 778-84. doi: 10.1089/jwh.2018.7264

7. National Comprehensive Cancer Network. Guidelines breast cancer. Version 5.2020. [internet]. Gradishar WJ, Anderson BO, Abraham J, Aft R, Agnese $\mathrm{D}$, Allison $\mathrm{KH}$, et al, editors. [cited 2020 Aug 22]. Available at: https://www. nccn.org/professionals/physician_gls/pdf/breast.pdf

8. Peccatori FA, Lambertini M, Scarfone G, Del Pup L, Codacci-Pisanelli G. Biology, staging, and treatment of breast cancer during pregnancy: reassessing the evidences. Cancer Biol Med 2018; 15: 6-13. doi: 10.20892/j. issn.2095-3941.2017.0146 
9. Gwyn KM, Theriault RL. Breast cancer during pregnancy. Curr Treat Options Oncol 2000; 1: 239-43. doi: 10.1007/s11864-000-0035-8

10. Genin AS, Lesieur B, Gligorov J, Antoine M, Selleret L, Rouzier R. Pregnancyassociated breast cancers: do they differ from other breast cancers in young women? Breast 2012; 21: 550-5. doi: 10.1016/j.breast.2012.05.002

11. Anders CK, Fan C, Parker JS, Carey LA, Blackwell KL, Klauber-DeMore N, et al. Breast carcinomas arising at a young age: unique biology or a surrogate for aggressive intrinsic subtypes? J Clin Oncol 2011; 29: e18-20. doi: 10.1200/ JCO.2010.28.9199

12. Murphy CG, Mallam D, Stein S, Patil S, Howard J, Sklarin N, et al. Current or recent pregnancy is associated with adverse pathologic features but not impaired survival in early breast cancer. Cancer 2012; 118: 3254-9. doi: 10.1002/cncr.26654

13. Claus EB, Schildkraut JM, Thompson WD, Risch NJ. The genetic attributable risk of breast and ovarian cancer. Cancer 1996; 77: 2318-24. doi: 10.1002/ (SICI)1097-0142(19960601)77:11<2318::AID-CNCR21>3.0.CO;2-Z

14. Peccatori FA, Azim HA Jr, Orecchia R, Hoekstra HJ, Pavlidis N, Kesic V, et al Cancer, pregnancy and fertility: ESMO Clinical Practice Guidelines for diagnosis, treatment and follow-up. Ann Oncol 2013; 24(Suppl 6): vi160-70. doi: 10.1093/annonc/mdt199

15. Loibl S, Schmidt A, Gentilini O, Kaufman B, Kuhl C, Denkert C, et al. Breast cancer diagnosed during pregnancy: adapting recent advances in breast cancer care for pregnant patients. JAMA Oncol 2015; 1: 1145-53. doi: 10.1001/jamaoncol.2015.2413

16. National Toxicology Program. NTP monograph: developmental effects and pregnancy outcomes associated with cancer chemotherapy use during pregnancy. NTP Monogr 2013; (2): i-214. PMID: 24736875

17. Nettleton J, Long J, Kuban D, Wu R, Shaefffer J, El-Mahdi A. Breast cance during pregnancy: quantifying the risk of treatment delay. Obstet Gynecol 1996; 87: 414-8. doi: 10.1016/0029-7844(95)00470-x

18. Azim HA Jr, Santoro L, Russell-Edu W, Pentheroudakis G, Pavlidis N, Peccator FA. Prognosis of pregnancy-associated breast cancer: a meta-analysis of 30 studies. Cancer Treat Rev 2012; 38: 834-42. doi: 10.1016/j.ctrv.2012.06.004

19. Amant F, von Minckwitz G, Han SN, Bontenbal M, Ring AE, Giermek J, et al. Prognosis of women with primary breast cancer diagnosed during pregnancy: results from an international collaborative study. J Clin Oncol 2013; 31: 2532-9. doi: 10.1200/JCO.2012.45.6335

20. U.S. Department of Health and Human Services. Common terminology criteria for adverse events (CTCAE) Version 5.0. [internet]. 2017. [cited 2020 Aug 21]. Available at: https://ctep.cancer.gov/protocoldevelopment/electronic applications/docs/CTCAE v5 Quick Reference 5x7.pdf

21. Martinez MT, Bermejo B, Hernando C, Gambardella V, Cejalvo JM, Lluch A. Breast cancer in pregnant patients: a review of the literature. Eur J Obste Gynecol Reprod Biol 2018; 230: 222-7. doi: 10.1016/j.ejogrb.2018.04.029

22. Novotny DB, Maygarden SJ, Shermer RW, Frable WJ. Fine needle aspiration of benign and malignant breast masses associated with pregnancy. Acto Cytol 1991; 35: 676-86. doi: 10.1016/j.ctrv.2012.06.004

23. Woo JC, Yu T, Hurd TC. Breast cancer in pregnancy: a literature review. Arch Surg 2003; 138: 91-8; discussion 9. doi: 10.1001/archsurg.138.1.91

24. Shachar SS, Gallagher K, McGuire K, Zagar TM, Faso A, Muss HB, et al. Multidisciplinary management of breast cancer during pregnancy. Oncologist 2017; 22: 324-34. doi: 10.1634/theoncologist.2016-0208

25. Yang WT, Dryden MJ, Gwyn K, Whitman GJ, Theriault R. Imaging of breast cancer diagnosed and treated with chemotherapy during pregnancy. Radiology 2006; 239: 52-60. doi: 10.1148/radiol.2391050083

26. Committee Opinion No. 723: Guidelines for diagnostic imaging during pregnancy and lactation. Obstet Gynecol 2017; 130: e210-e6. doi: 10.1097/ AOG.0000000000002355

27. Nguyen CP, Goodman LH. Fetal risk in diagnostic radiology. Semin Ultrasound CTMR 2012; 33: 4-10. doi: 10.1053/j.sult.2011.09.003

28. Thomsen HS. Contrast media safety-an update. Eur J Radiol 2011; 80: 77-82. doi: 10.1016/j.ejrad.2010.12.104

29. Committee Opinion No. 696: Nonobstetric surgery during pregnancy Obstet Gynecol 2017; 129: 777-8. doi: 10.1097/AOG.0000000000002014

30. Amant F, Deckers S, Van Calsteren K, Loibl S, Halaska M, Brepoels L, et al. Breast cancer in pregnancy: recommendations of an international consensus meeting. Eur J Cancer 2010; 46: 3158-68. doi: 10.1016/j. ejca.2010.09.010
31. Toesca A, Gentilini O, Peccatori F, Azim HA Jr, Amant F. Locoregional treatment of breast cancer during pregnancy. Gynecol Surg 2014; 11: 279-84. doi: 10.1007/s10397-014-0860-6

32. Gropper AB, Calvillo KZ, Dominici L, Troyan S, Rhei E, Economy KE, et al. Sentinel lymph node biopsy in pregnant women with breast cancer. Ann Surg Oncol 2014; 21: 2506-11

33. Khera SY, Kiluk JV, Hasson DM, Meade TL, Meyers MP, Dupont EL, et al. Pregnancy-associated breast cancer patients can safely undergo lymphatic mapping. Breast J 2008; 14: 250-4. doi: 10.1111/j.1524-4741.2008.00570.x

34. Gentilini O, Cremonesi M, Toesca A, Colombo N, Peccatori F, Sironi R, et al. Sentinel lymph node biopsy in pregnant patients with breast cancer. Eur J Nucl Med Mol Imaging 2010; 37: 78-83. doi: 10.1007/s00259-009-1217-7

35. Fernandez-Delgado J, Lopez-Pedraza MJ, Blasco JA, Andradas-Aragones E, Sanchez-Mendez JI, Sordo-Miralles G, et al. Satisfaction with and psychological impact of immediate and deferred breast reconstruction. Ann Oncol 2008; 19: 1430-4. doi: 10.1093/annonc/mdn153

36. Mazzola R, Corradini S, Eidemueller M, Figlia V, Fiorentino A, Giaj-Levra N, et al. Modern radiotherapy in cancer treatment during pregnancy. Crit Rev Oncol Hematol 2019; 136: 13-9. doi: 10.1016/j.critrevonc.2019.02.002

37. Raphael J, Trudeau ME, Chan K. Outcome of patients with pregnancy during or after breast cancer: a review of the recent literature. Curr Oncol 2015; 22 S8-18. doi: 10.3747/co.22.2338

38. Beadle BM, Woodward WA, Middleton LP, Tereffe W, Strom EA, Litton JK, et al. The impact of pregnancy on breast cancer outcomes in women. Cancer 2009; 115: 1174-84. doi: 10.1002/cncr.24165

39. Van Calsteren K, Verbesselt R, Ottevanger N, Halaska M, Heyns L, Van Bree $\mathrm{R}$, et al. Pharmacokinetics of chemotherapeutic agents in pregnancy: a preclinical and clinical study. Acta Obstet Gynecol Scand 2010; 89: 1338-45. doi: $10.3109 / 00016349.2010 .512070$

40. Cardonick E, Gilmandyar D, Somer RA. Maternal and neonatal outcomes of dose-dense chemotherapy for breast cancer in pregnancy. Obstet Gynecol 2012; 120: 1267-72. doi: 10.1097/AOG.0b013e31826c32d9

41. Hahn KM, Johnson PH, Gordon N, Kuerer H, Middleton L, Ramirez M, et al. Treatment of pregnant breast cancer patients and outcomes of children exposed to chemotherapy in utero. Cancer 2006; 107: 1219-26. doi: 10.1002/ cncr.22081

42. Murthy RK, Theriault RL, Barnett CM, Hodge S, Ramirez MM, Milbourne A, et al. Outcomes of children exposed in utero to chemotherapy for breas cancer. Breast Cancer Res 2014; 16: 500. doi: 10.1186/s13058-014-0500-0

43. Gziri MM, Hui W, Amant F, Van Calsteren K, Ottevanger N, Kapusta L, et al. Myocardial function in children after fetal chemotherapy exposure. a tissue Doppler and myocardial deformation imaging study. Eur J Pediatr 2013; 172: 163-70. doi: 10.1007/s00431-012-1849-7

44. Berveiller $\mathrm{P}$, Mir $\mathrm{O}$. Taxanes during pregnancy: probably safe, but still to be optimized. Oncology 2012; 83: 239-40. doi: 10.1159/000341820

45. Zagouri F, Sergentanis TN, Chrysikos D, Dimitrakakis C, Tsigginou A, Zografos CG, et al. Taxanes for breast cancer during pregnancy: a systematic review. Clin Breast Cancer 2013; 13: 16-23. doi: 10.1016/j.clbc.2012.09.014

46. Lambertini M, Peccatori FA, Azim HA Jr. Targeted agents for cancer treatment during pregnancy. Cancer Treat Rev 2015; 41: 301-9. doi: 10.1016/j. ctrv.2015.03.001

47. Isaacs RJ, Hunter W, Clark K. Tamoxifen as systemic treatment of advanced breast cancer during pregnancy - case report and literature review. Gynecol Oncol 2001; 80: 405-8. doi: 10.1006/gyno.2000.6080

48. Cullins SL, Pridjian G, Sutherland CM. Goldenhar's syndrome associated with tamoxifen given to the mother during gestation. JAMA 1994; 271: 1905-6. doi: 10.1001/jama.1994.03510480029018

49. Fejzo MS, MacGibbon KW, Mullin PM. Ondansetron in pregnancy and risk of adverse fetal outcomes in the United States. Reprod Toxicol 2016; 62: 87-91. doi: 10.1016/j.reprotox.2016.04.027

50. Anderka M, Mitchell AA, Louik C, Werler MM, Hernandez-Diaz S, Rasmussen SA. Medications used to treat nausea and vomiting of pregnancy and the risk of selected birth defects. Birth Defects Res A Clin Mol Teratol 2012; 94: 22-30. doi: 10.1002/bdra.22865

51. Xiaoxiao P, Li L, Li M, Qian Z, Chenghao L. [Preliminary study on E-cadherin expression in dexamethasone-induced palatal cleft in mouse]. [Chinese]. Hua Xi Kou Qiang Yi Xue Za Zhi 2015; 33: 581-4. doi: 10.7518/hxkq.2015.06.006 